\title{
Minimization of Network Power Losses in the AC-DC Hybrid Distribution Network through Network Reconfiguration Using Soft Open Point
}

\author{
Muhammad Omer Khan 1,+, Abdul Wadood ${ }^{2, *}$, Muhammad Irfan Abid ${ }^{1}$ (D), Tahir Khurshaid ${ }^{3,+} \mathbb{D}$ \\ and Sang Bong Rhee ${ }^{3, *}$ \\ 1 Department of Electrical Engineering \& Technology, Faisalabad Campus, Riphah International University, \\ Punjab 38000, Pakistan; omerkhan@riphahfsd.edu.pk (M.O.K.); mirfanabid@riphahfsd.edu.pk (M.I.A.) \\ 2 Department of Electrical Engineering, Air University Islamabad, Kamra 43570, Pakistan \\ 3 Department of Electrical Engineering, Yeungnam University, Gyeongsan-si 38541, Korea; tahir@ynu.ac.kr \\ * Correspondence: wadood@au.edu.pk (A.W.); rrsd@yu.ac.kr (S.B.R.) \\ + These authors contributed equally to this work and considered as co-first author.
}

\begin{abstract}
The Alternating Current-Direct Current (AC-DC) hybrid distribution network has received attention in recent years. Due to advancement in technologies such as the integration of renewable energy resources of DC-type output and usage of DC loads in the distribution network, the modern distribution system can meet the increasing energy demand with improved efficiency. In this paper, a new AC-DC hybrid distribution network architecture is analyzed that considers distributed energy resources (DER) in the network. A network reconfiguration scheme is proposed that uses the AC soft open point (AC-SOP) and the DC soft open point (DC-SOP) along with an SOP selection algorithm for minimizing the network power losses. Subsequently, the real-time data for DER and load/demand variation are considered for a day-a-head scenario for the verification of the effectiveness of the network reconfiguration scheme. The results show that the proposed network reconfiguration scheme using AC-SOP and DC-SOP can successfully minimize the network power losses by modifying the network configuration. Finally, the effectiveness of the proposed scheme in minimizing the network power losses by the upgraded network configuration is verified by constructing an AC-DC hybrid distribution network by combining two IEEE 33-bus distribution networks.
\end{abstract}

Keywords: AC-DC hybrid distribution network; power flow analysis; soft open point; network reconfiguration

\section{Introduction}

An increase in concerns about global climate change by reducing carbon emissions and limitation of fossil fuel resources has resulted in an increase in the use of distributed energy resources (DER), due to their potential benefits [1]. On the other hand, recent developments in the power electronics area has resulted in an advancement in a distribution network. As compared to the advantages of the conventional AC distribution network and DC distribution network [2,3], the most practical network architecture for the future distribution systems is an AC-DC hybrid distribution network [4]. The advantages of a AC-DC hybrid distribution network can be highlighted in terms of the use of simplified equipment for end-users, reduction in power conversion losses, and efficient integration of DERs [5]. Power electronic devices are playing an imperative role in changing the traditional distribution network to a technological advance network and are applied for different purposes [6-8]. A smart power router based on a voltage source converter (VSC) was proposed and analyzed in [6] for minimizing the load shedding in the distribution system. A power electronics-based grid interconnector was proposed in [7] to decouple the frequency and voltage from the upstream network, while power flow controllers were 
proposed in [8] in implementing an active meshed distribution network from a loop network. In the distribution network, the power electronics device known as soft open points (SOPs) is proposed to replace the mechanically controlled normally open point (NOPs) to combine the advantages of both a radial and loop (mesh)-operated network $[9,10]$. The advantages of using SOPs as compared to network reconfiguration can be summarized as [9,10]: (1) uninterrupted power flows, (2) flexible controllability of active and reactive power, (3) peak current control due to fault, (4) efficient and reliable interconnection of multiple feeders. However, the above proposed SOPs can be classified as AC-SOPs which are utilized in the AC network for network reconfiguration, these AC-SOPs are based on voltage-source converters (VSC) by interconnecting two VSCs in a back-to-back style. On the other hand, the DC-SOP is proposed for the DC system and its operation and control modes are discussed in [11,12]. The literature on available SO devices till now was limited to only a few snapshots and did not cover the control strategies under different load and generation conditions over a time duration $[13,14]$. The AC/DC hybrid network at the distribution level has a high application-oriented nature for a future grid. On the other hand, the nature of the distribution network layout and the integration of the distribution generations are compelling for the study of such strategies, so that the network can operate effectively and efficiently. This network re-configuration approach can be helpful in the stable network operation while using the AC-SOP and the DC-SOP in the AC-DC hybrid distribution network.

\section{Contribution and Novelties}

The contribution of this work is to propose a new methodology to allocate SOPs and DGs simultaneously and to consider possible multi-scenario configurations from random configurations. In addition, this approach is used to investigate the contribution of SOP to the total active losses, as well as the effect of increasing the number of SOPs connected to the studied systems under different loading conditions to determine the real benefits gained from each strategy. Further, multi-scenario studies, which aim to improve the investigation of the overall performance of the strategies, are conducted on two IEEE 33node-balanced benchmark distribution systems integrated as a hybrid AC-DC distribution network. It is clear from the results obtained that placing SOPs and DGs into a distribution system creates a hybrid configuration that merges the benefits offered by radial and meshed distribution systems and mitigates drawbacks related to losses. Furthermore, it is clear that the allocation of SOPs and DGs with a network reconfiguration provide the best operation of distribution networks with minimum losses and an enhanced overall performance of the AC-DC distribution network.

The main contributions of this work can be summarized as:

(1) The AC-DC hybrid distribution network architecture based on AC-SOP and DC-SOP is proposed.

(2) The modeling, control, and operating principle of an AC-SOP and DC-SOP is formulated.

(3) The potential benefits of SOPs in achieving the network reconfiguration flexibility are proposed.

(4) An algorithm is proposed for network loss reduction in the AC-DC hybrid distribution network, considering the key elements of AC-SOP and DC-SOP.

In this paper, a network reconfiguration algorithm is proposed using the AC-SOP and the DC-SOP in the AC-DC hybrid distribution network for the reduction of network power losses. The scheme is verified by taking a case study with a modified two IEEE 33-bus distribution network, and the results show that the network power losses are efficiently minimized. 


\section{System Description}

\subsection{Description of the Generic AC-DC Hybrid Distribution Network}

An AC-DC hybrid distribution network consists of several AC sub-networks and DC sub-networks as well as DERs considered to be connected at various locations within the network as shown in Figure 1.

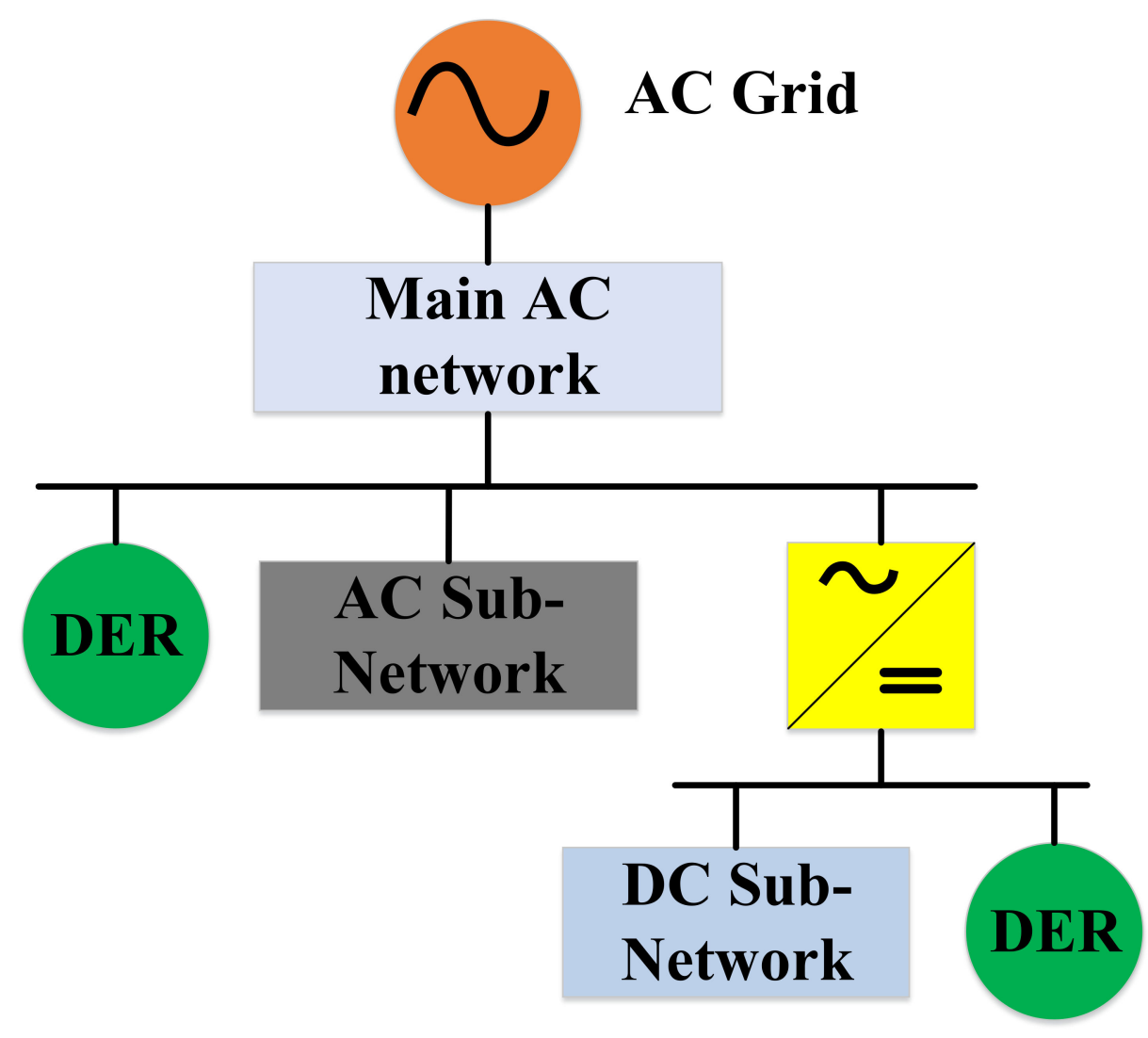

Figure 1. The generic architecture of AC-DC hybrid distribution network.

\subsection{Modelling of SOP}

In place of normally open points tie switches, the power electronic-controlled devices, SOPs $[9,10]$, are primarily used in the AC-DC hybrid distribution network. The AC-SOP and the DC-SOP constructed from the VSCs are the two types of SOPs which are used in this study for the AC and DC distribution networks, respectively.

(1) AC-SOP: Figure 2 illustrates the single line representation of the hybrid AC-DC distribution network with AC-SOP. Back-to-back VSCs are used for the construction of AC-SOP which are utilized for the interconnection of the feeder endpoints in the two AC distribution sub-networks. The ability of the AC-SOP is to control the active and reactive power under different power flow control modes [11].

(2) DC-SOP: Similarly, DC-SOP is also located at the end of the DC distribution network feeders. Figure 3 shows the single line diagram of the DC soft open point (DC-SOP) in the AC-DC hybrid distribution network. 


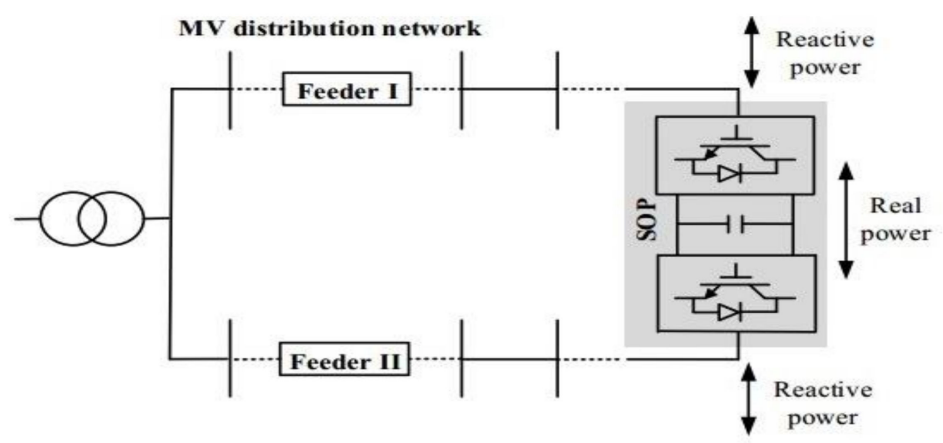

(a)

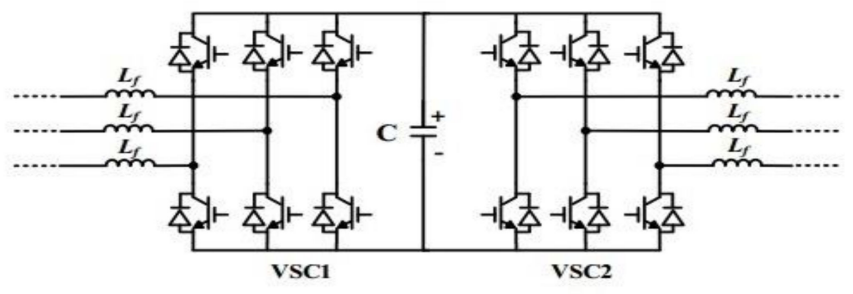

(b)

Figure 2. The single line diagram of the hybrid AC-DC distribution network with AC-soft open points (SOPs) (a) Basic configuration of the distribution network and the AC soft open point (AC-SOP). (b) Main circuit topology of the voltage source converter (VSC)-based AC-SOP.

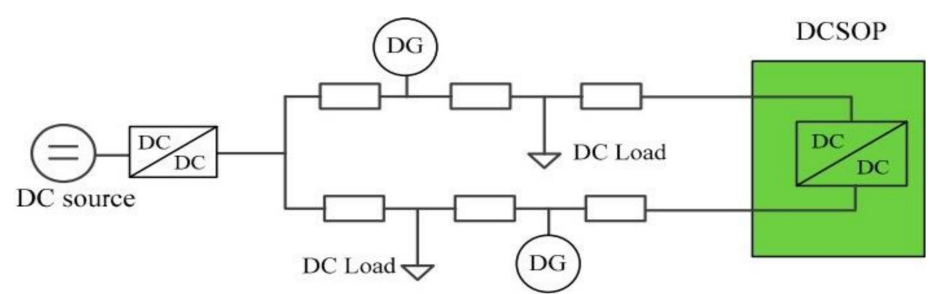

(a)

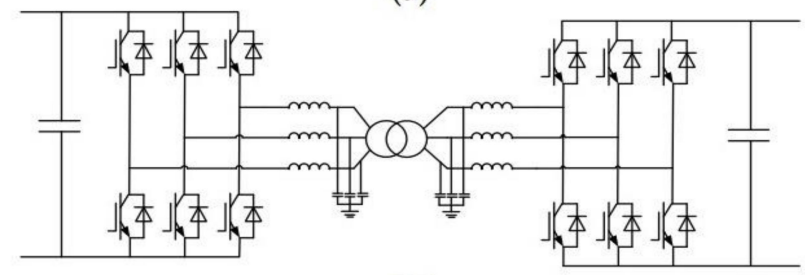

(b)

Figure 3. The single line diagram of the hybrid AC-DC distribution network with DC-SOP (a) Basic configuration of the distribution network and the DC soft open point (DC-SOP). (b) Main circuit topology of the VSC-based DC-SOP.

\section{Problem Formulation}

\subsection{Power Balance Equations}

The power balance equations for AC sub-networks can be formulated as

$$
\begin{gathered}
P_{G i}-P_{D i}-U_{i} \sum_{j \in N_{A C}} U_{j}\left[G_{i j} \cos \left(\delta_{i j}\right)+B_{i j} \sin \left(\delta_{i j}\right)\right]=0, \forall i \in N_{A C} \\
Q_{G i}-Q_{D i}-U_{i} \sum_{j \in N_{A C}} U_{j}\left[G_{i j} \sin \left(\delta_{i j}\right)-B_{i j} \cos \left(\delta_{i j}\right)\right]=0, \forall i \in N_{A C}
\end{gathered}
$$


The power balance equations for DC sub-networks can be shown as

$$
P_{G i}-P_{D i}-U_{i} \sum_{j \in N_{D C}}\left(U_{i}-U_{j}\right) G_{i j}=0, \forall i \in N_{D C}
$$

where $P_{G i}$ and $Q_{G i}$ are the active and reactive power injection at bus $i$, respectively; $P_{D i}$ and $Q_{D i}$ are the active and reactive loads at bus $i ; V i$ and $V j$ are the node voltages of the bus $i$ and bus $j$, respectively; $G i j, B i j$, and $\theta i j$ are the conductance, susceptance, and the phase angle difference between bus $i$ and bus $j$, respectively.

\subsection{Voltage and Line Parameters}

The voltage parameter for each bus is shown by

$$
U_{\min (}(i) \leq U(i) \leq U_{\max (}(i), \forall i \in N_{D C} \cup N_{D C}
$$

where $U(i)$ is the node voltage of the bus $i ; U_{\max (i)}$ and $U_{\min (i)}$ are the upper and lower voltage limits of the bus $i$, respectively. The limits of power flowing through line can be shown as

$$
S_{\text {line,max }} \leq S_{\text {line }} \leq S_{\text {line, } \max }
$$

where $S_{\text {line }}$ represents the apparent power flowing in the network lines; $S_{\text {line,max }}$ represents the allowed maximum power flow.

\subsection{AC-DC Converter Modeling}

A steady-state model of the AC-DC converter in Figure 4 has been discussed in detail in [15-17]. In this model, the VSC acts as a controllable voltage source behind complex admittance. This complex admittance can be distinguished among the admittance of the interface transformer $\mathrm{Ytf}=\mathrm{Gtf}+\mathrm{jBtf}$, the susceptance of the low pass filter $\mathrm{jBf}$, and the admittance of phase reactors $\mathrm{YC}_{\mathrm{C}}=\mathrm{GC}+\mathrm{jBc}$. $\mathrm{U}_{\mathrm{AC}}=\mathrm{U}_{\mathrm{AC}} \angle \delta_{\mathrm{AC}}$ represents the voltage output at $\mathrm{AC}$ bus, $\mathrm{Uc}_{\mathrm{C}}=\mathrm{Uc}_{\mathrm{c}} \angle \delta \mathrm{c}$ expresses the output voltage at converter bus, and $\mathrm{U}_{\mathrm{DC}}$ is the $\mathrm{DC}$ bus output voltage. The connected filter voltage is represented by $\mathrm{Uf}=\mathrm{Uf} \angle \delta \mathrm{f}$. The power injected to the $A C$ system is represented by $P_{A C}$ and $Q_{A C}$, and the power flowing to the AC network from the converter side is $\mathrm{Pc}$ and $\mathrm{Qc}$, while the DC power is shown by $\mathrm{P}_{\mathrm{DC}}$.

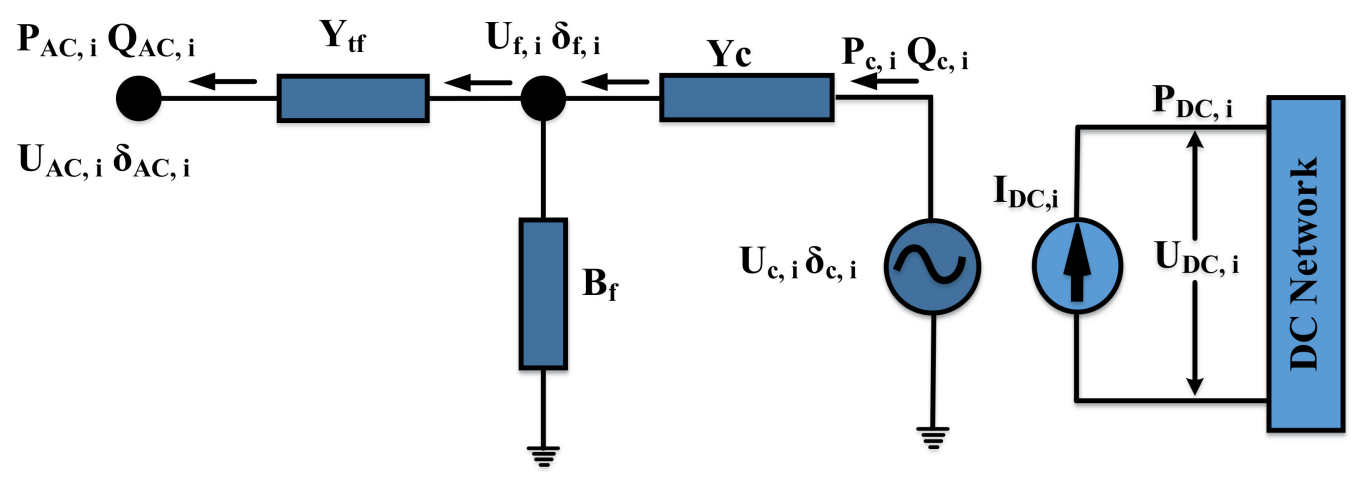

Figure 4. The steady-state model of the AC-DC converter.

The exchange of power between the AC-sub-network and the DC-sub-network takes place at the VSC interlinking the sub-networks. Figure 4 shows the voltage source converter steady state model used in this approach.

\subsection{Constraints of SOP}

The operational constraints of the AC-SOP and DC-SOP under normal operating conditions are discussed in this section. 
(1) AC-SOP constraints: The operation of the AC-SOP is shown in Figure 5. In the power flow control mode [11], both the VSCs independently generate the voltage waveforms, which effectively results in a full control of the power at the two AC terminals of the VSCs. In this configuration of the AC-SOP, three variables are independently controlled, i.e., the active power PAC1 output of VSC1 and the reactive power outputs $\mathrm{QAC1}$, and QAC2 of the two VSCs, respectively.

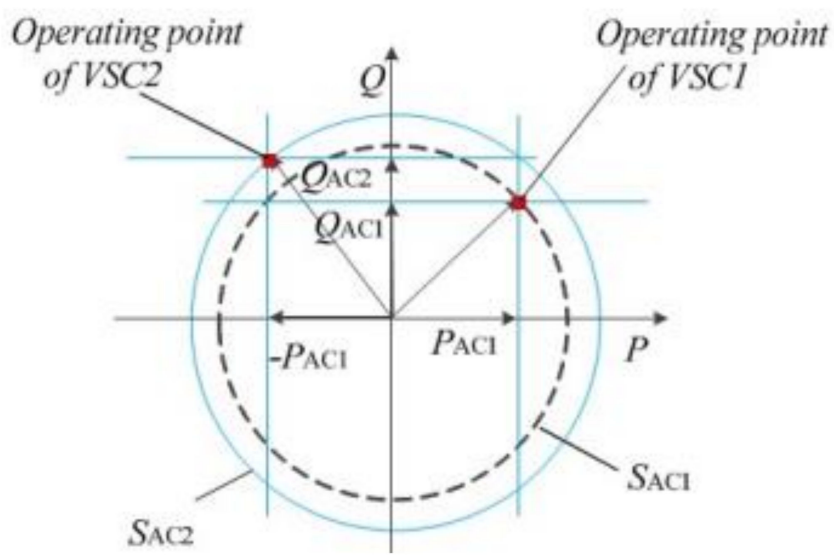

Figure 5. AC-SOP operation curve for power flow control.

The operation constraints of an AC-SOP are as follows:

$$
P_{S O P-A C 1}+P_{S O P-A C 2}+P_{\text {loss }, S O P-A C}=0
$$

where $P_{S O P-A C 1}$ and $P_{S O P-A C 2}$ are the active power flowing through each VSC of the SOP, and $P_{S O P, l o s s}-A C$ is the power losses in the SOP. The constraints on the SOP terminal voltages and power capacity are:

$$
\begin{gathered}
U_{S O P-A C 1} \leq U_{S O P-A C 1, \text { rated }} \\
U_{S O P-A C 2} \leq U_{S O P-A C 2, \text { rated }} \\
\sqrt{P^{2} S O P-A C 1+Q^{2} S O P-A C 1} \leq S_{S O P-A C 1} \\
\sqrt{P^{2} S O P-A C 2+Q^{2} S O P-A C 2} \leq S_{S O P-A C 2}
\end{gathered}
$$

where $Q_{S O P-A C}$ and $Q_{S O P-A C 2}$ are the reactive power from the two VSCs, respectively; $S_{S O P-A C 1}$ and $S_{S O P-A C 2}$ are the corresponding ratings;

$U_{S O P-A C 1, \text { rated }}$ and $U_{S O P-A C 2, \text { rated }}$ are the upper limits of the terminal voltage for each VSC.

(2) DC-SOP constraints: The DC-SOP operates in the constant active power control mode, as no reactive power is involved in the DC network. The constraints for the operation of a DCSOP can be represented as:

$$
P_{S O P-D C 1}+P_{S O P-D C 2}+P_{\text {loss }, S O P-D C}=0
$$

The operation of a DC-SOP is constrained as follows

$$
\begin{gathered}
U_{S O P-D C 1} \leq U_{S O P-D C 1, \text { rated }} \\
U_{S O P-D C 2} \leq U_{S O P-D C 2, \text { rated }} \\
\left|P_{S O P-D C 1}\right| \leq P_{S O P-A C 1, \text { rated }}
\end{gathered}
$$




$$
\left|P_{S O P-D C 2}\right| \leq P_{S O P-A C 2, \text { rated }}
$$

where $P_{S O P-D C 1}$ and $P_{S O P-D C 2}$ represent the active power in the two VSCs; $P_{S O P-D C 1}$, rated, and $P_{S O P-D C 2}$ rated represent the maximum active power transferred limit by the VSCs; $P_{\text {SOPloss }-D C}$ is the losses in the DC-SOP; $\mathrm{U}_{\mathrm{SOP}-\mathrm{DC} 1}$, rated, and $U_{S O P-D C 2, r}$ rated represent the upper limits of the VSCs' terminal voltages. The control modes of a DC-SOP can be summarized in Table 1 .

Table 1. DC-Soft Open Point (DC-SOP) control modes.

\begin{tabular}{ccc}
\hline Control Modes & VSC1 & VSC2 \\
\hline 1 & $\mathrm{P}_{\mathrm{DC} \_ \text {VSC1 }}$ control & $\mathrm{U}_{\mathrm{AC} \text { _VSC2 }}$ control \\
2 & $\mathrm{U}_{\mathrm{AC} \_ \text {VSC1 }}$ control & P $_{\mathrm{DC} \text { VSSC2 }}$ control \\
\hline
\end{tabular}

\section{Network Reconfiguration Scheme and Case Study}

The configuration of a conventional power distribution network is radial in nature and normally open point (NOP) mechanical tie switches are the device used to achieve the modification of network reconfiguration. As an alternative, to achieve an efficient and fast network modification in network configuration, an electronic-based device known as soft open point (SOP) can be used to replace the NOP. The advantages offered by SOP are flexibility and reliability in network reconfiguration and efficient network restoration, due to any fault or outage. In this study, the network reconfiguration of AC-DC hybrid distribution network is used to achieve a better network operation in terms of the reduction in network power loss and, hence, increase the efficiency of the network.

\subsection{SOP/Loop Selection Algorithm for Network Reconfiguration}

Here, a flowchart of the SOP/loop selection algorithm is presented in Figure 6 to achieve the reduction in the network power losses. A step-by-step description of the $\mathrm{SOP} /$ loop selection algorithm for the SOP operation is as follows.

Step 1: Observe the original distribution network configuration and observe the soft open point switch locations.

Step 2: Carry out the power flow calculations [4] for the AC-DC hybrid distribution network for a period of 24-h considering each soft open point switches individually.

Step 3: Calculate accumulated voltage $\left(A V_{A C-S O P}\right.$ and $\left.A V_{D C-S O P}\right)$ across each soft open point $(A C-S O P$ and $D C-S O P)$ switches in the $A C$ network and $D C$ network respectively, according to Equations (16) and (17):

$$
\begin{aligned}
& A V_{A C-S O P, n}=\sum_{h r=1}^{24}\left|V_{S O P \_n \_h r}\right|=\sum_{h r=1}^{24}\left|V_{A C, i}-V_{A C, j}\right| \\
& A V_{D C-S O P, n}=\sum_{h r=1}^{24}\left|V_{S O P \_n \_h r}\right|=\sum_{h r=1}^{24}\left|V_{D C, i}-V_{D C, j}\right|
\end{aligned}
$$

where $n=$ Tie switch number; $V_{S O P \_n \_h r}=$ Open voltage at SOP switch ' $n$ ' at hour ' $h r$ '.

Step 4: If all $A V_{A C-S O P}$ and $A V_{D C-S O P}$ calculations for soft open switches are completed, calculate the total $A V$ according to Equations (18) and (19) for each case

$$
\begin{aligned}
& \text { Total } A V_{A C-S O P, n}=\sum A V_{A C-S O P, n} \\
& \text { Total } A V_{D C-S O P, n}=\sum A V_{D C-S O P, n}
\end{aligned}
$$

Step 5: Select the case with the maximum value of total $A_{V A C-S O P}$ and $A V_{D C-S O P}$. Select the SOP (AC-SOP or DC-SOP) with the largest voltage imbalance and operate, then estimate the reduction in the network power losses. 


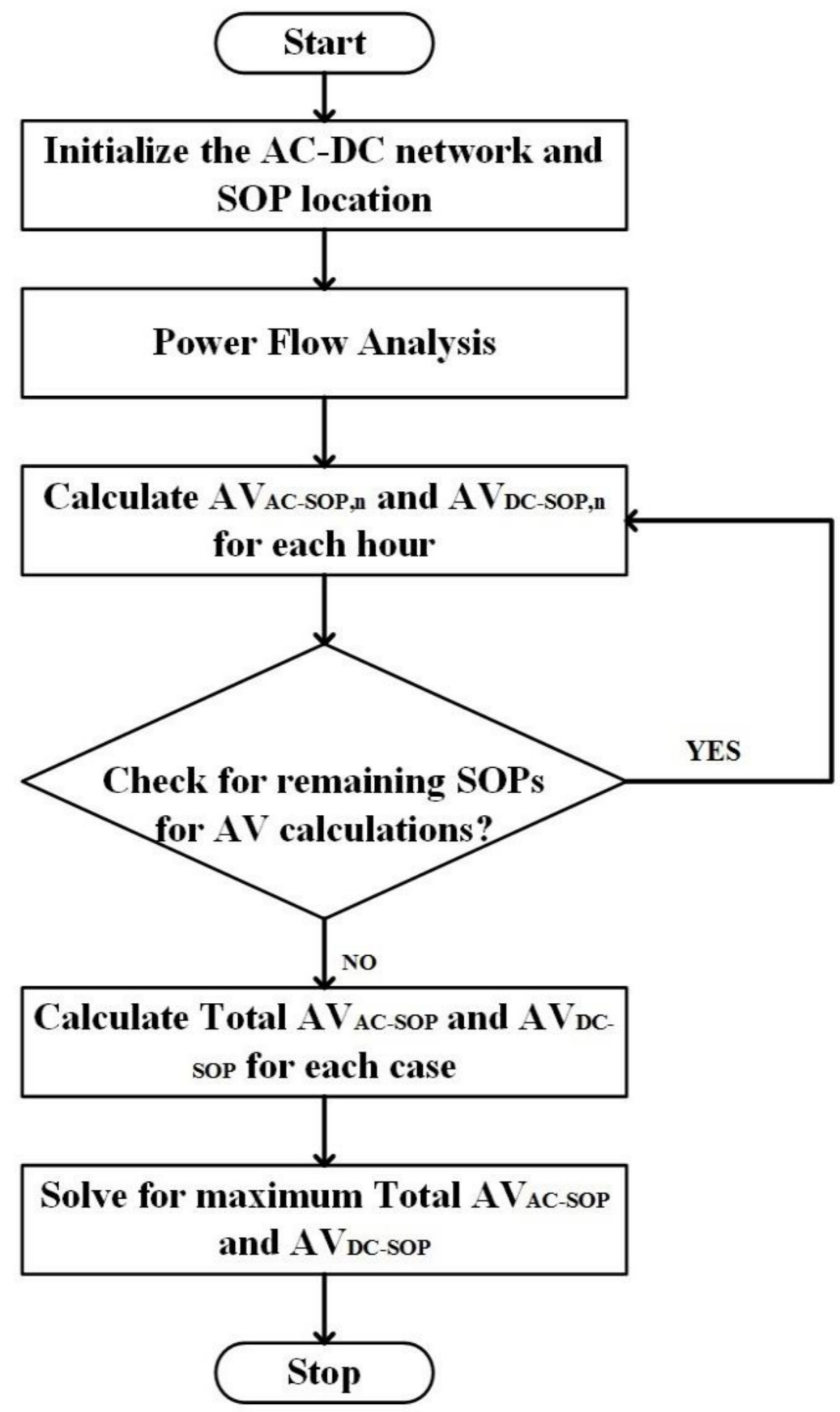

Figure 6. Flowchart of SOP/loop selection algorithm for reduction in the network power losses.

\subsection{Case Study}

In this study, two IEEE 33-bus distribution networks are interconnected to form the AC-DC hybrid distribution network, as shown in Figure 7. In this test system, ten SOP switches are considered at different locations. Five of the AC-SOPs are placed between buses 18 and 22, 18 and 25, 18 and 33, 22 and 25, and 25 and 33. Similarly, five of the DC-SOPs are considered to be placed between buses 51 and 55, 51 and 58, 51 and 66, 55 and 58 , and 58 and 66. A total of twelve distributed energy resources (DER) in which six of the DER consist of wind turbines with rated capacities of $400 \mathrm{~kW}$ each and the rest of the six DER consist of solar photovoltaic(PV) panels with rated capacities of $200 \mathrm{~kW}$ each. For this case study, real-time data for the load [18], wind energy [19], and PV generation [20] are considered. The 24-h load, wind energy, and PV generation profiles are shown in Figure 8. 


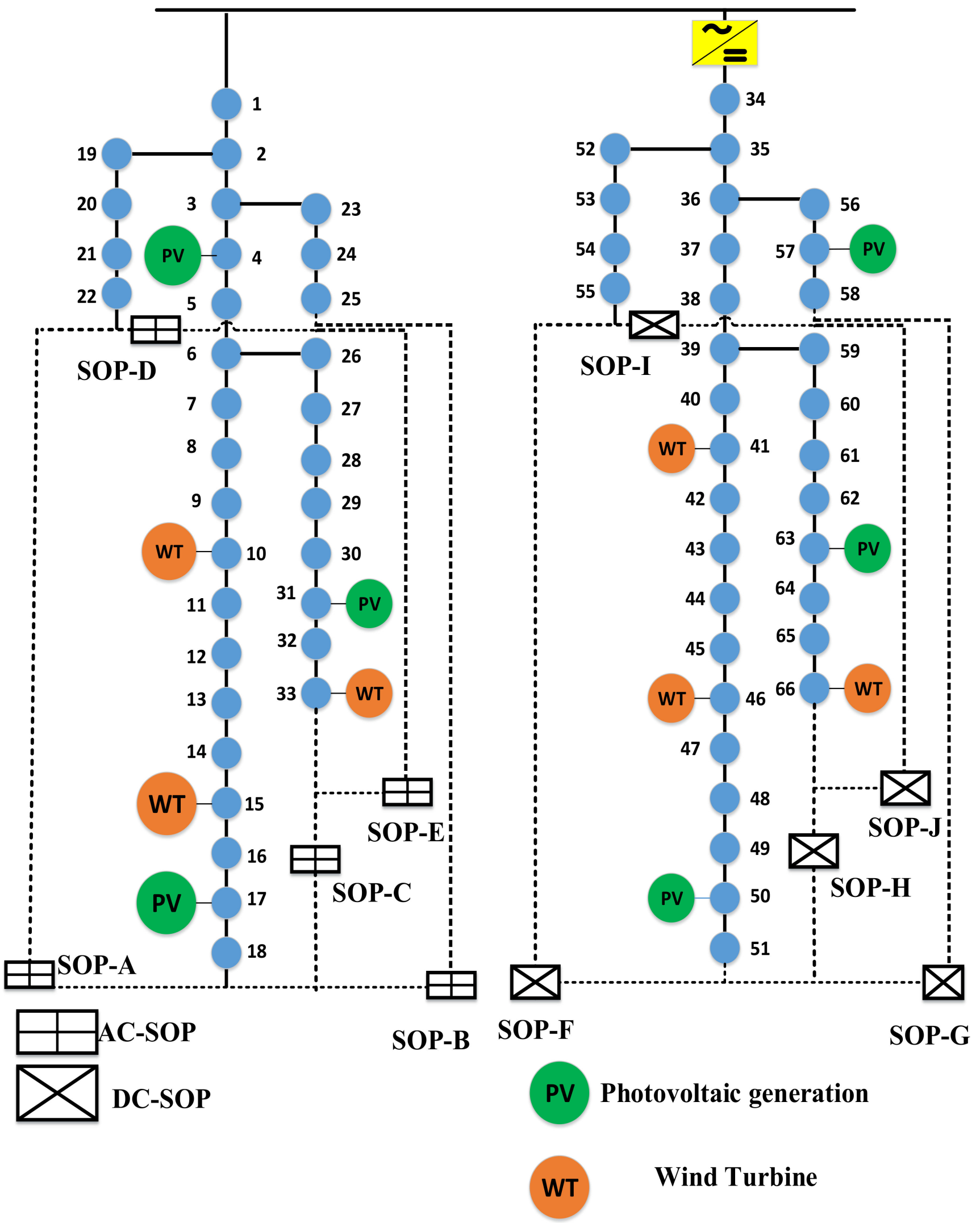

Figure 7. Two IEEE 33-node distribution networks modified into AC-DC hybrid distribution network with SOPs. 


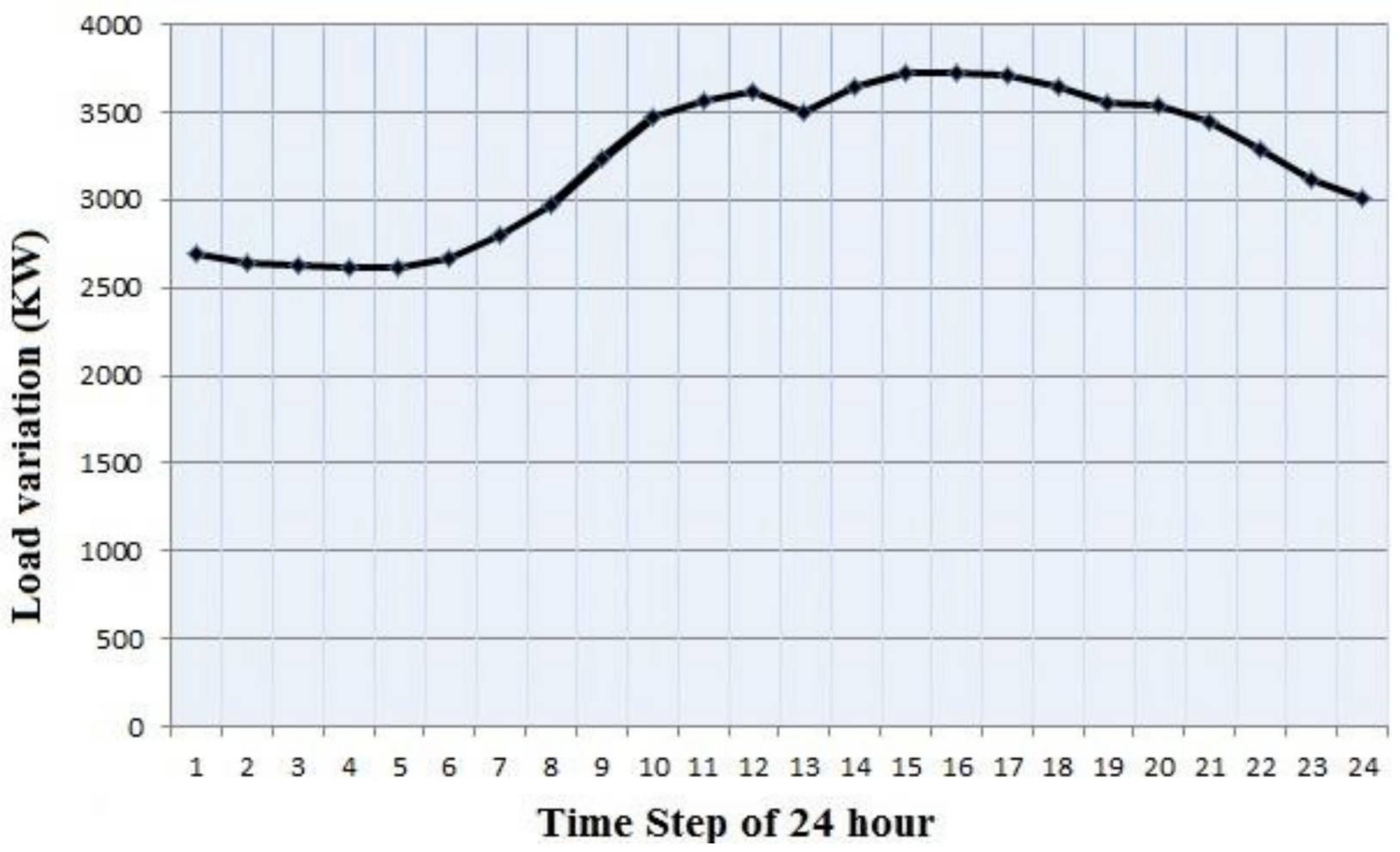

(a)

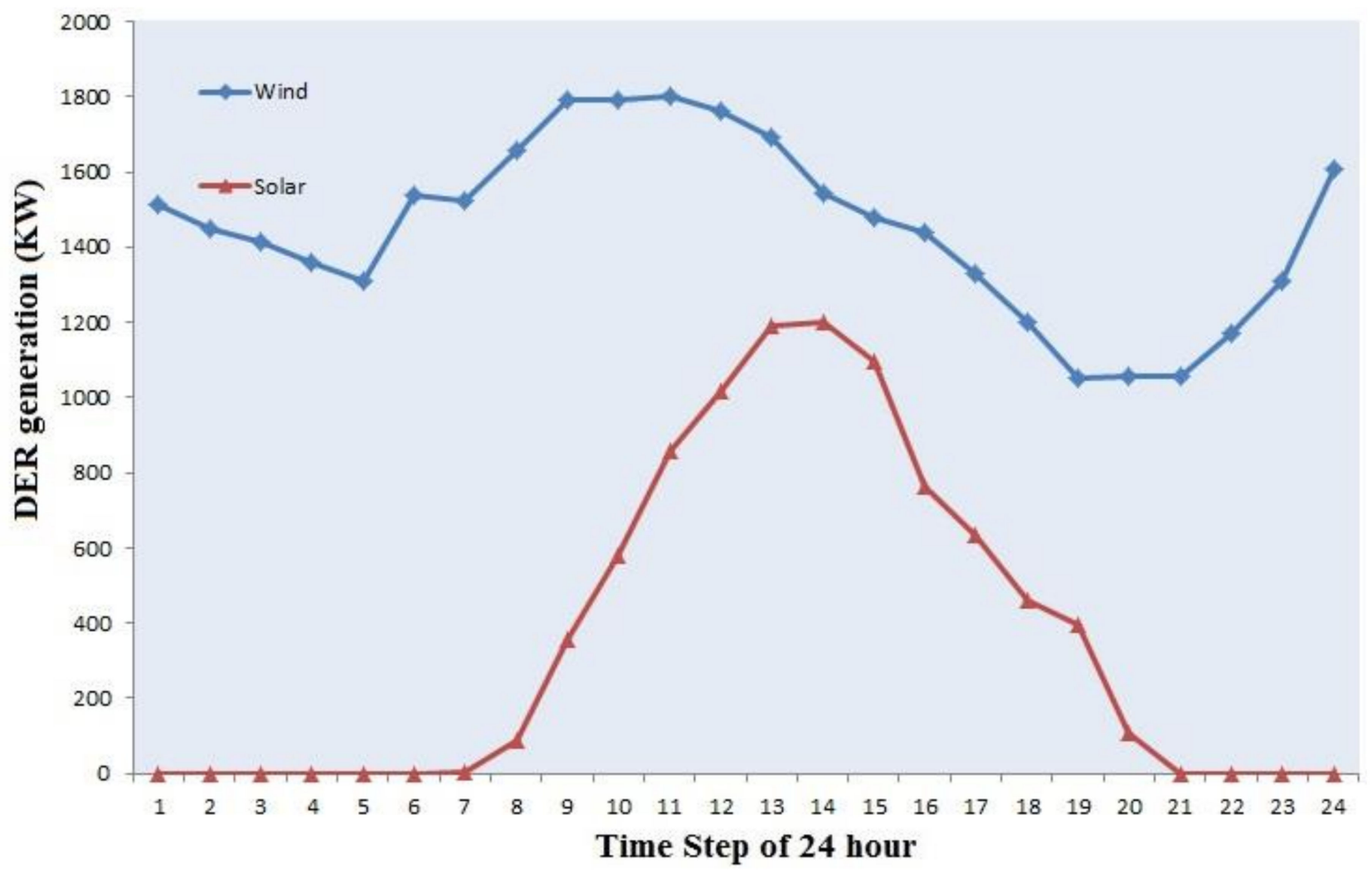

(b)

Figure 8. (a) Profile of load variation for a 24-h period. (b) Profile of wind and PV generation for a 24-h period. 
All the test cases considered in this study are summarized in Table 2.

Table 2. Test cases for AC-SOP and DC-SOP.

\begin{tabular}{cccc}
\hline \multicolumn{2}{c}{ AC-SOP } & \multicolumn{2}{c}{ DC-SOP } \\
\hline Case & SOP Location & Case & SOP Location \\
\hline Case A & $18-22$ & Case F & $51-55$ \\
Case B & $18-25$ & Case G & $51-58$ \\
Case C & $18-33$ & Case H & $51-66$ \\
Case D & $22-25$ & Case I & $55-58$ \\
Case E & $25-33$ & Case J & $58-66$ \\
\hline
\end{tabular}

\subsection{Simulation Result}

To analyze the results, a power flow analysis is conducted and the total AVs for each case (AC-SOP and DC-SOP) are calculated using the SOP/loop selection algorithm. The total AVAC-SOP for all the SOP in the AC network are shown in Figure 9.

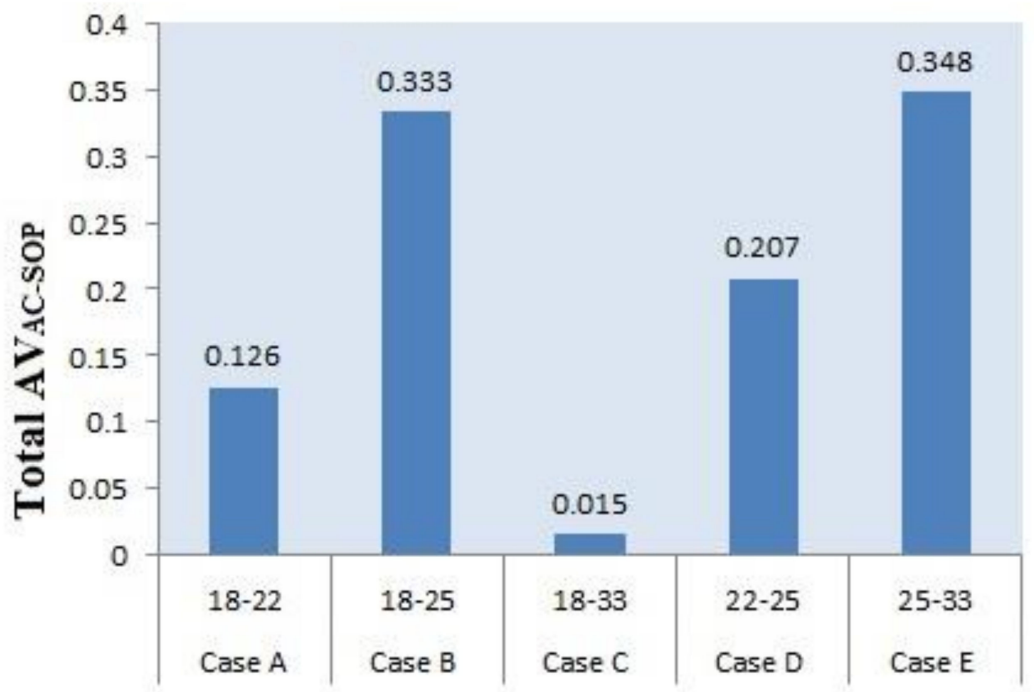

Figure 9. Total accumulated voltage (AV) calculations for AC-SOP.

Results show that the total $\mathrm{AV}_{\mathrm{AC}-\mathrm{SOP}}$ is the highest in the cases of $\mathrm{E}$ and $\mathrm{B}$, while it is the worst case in terms of total $\mathrm{AV}_{\mathrm{AC}-\mathrm{SOP}}$ in the case of $\mathrm{C}$. As per the proposal of the SOP/loop selection algorithm, the operation of the AC-SOP switch between feeders 25 and 33 (Case E) and between feeders 18 and 25 (Case B) will cause the reduction of network power losses, while the AC-SOP switch between feeder 18 and 33 (Case C) will have a worse performance regarding the reduction of network power losses. These results are verified and are shown in Table 3.

Table 3. Reducing the network power losses for each accumulated voltage $\left(\mathrm{AV}_{\mathrm{AC}-\mathrm{SOP}}\right)$ installed in the $\mathrm{AC}-\mathrm{DC}$ hybrid distribution network for a $24-\mathrm{h}$ period.

\begin{tabular}{lllllll}
\hline AC-SOP & No SOP & Case A & Case B & Case C & Case D & Case E \\
\hline $\mathrm{AV}$ AC-SOP & 0 & 0.126 & 0.333 & 0.015 & 0.207 & 0.348 \\
$\mathrm{AC}$ losses $(\mathrm{kWh})$ & 374.6 & 371.04 & 366.72 & 371.28 & 369.84 & 363.36 \\
$\mathrm{AC}$ losses reduction $(\%)$ & 0 & 0.950 & 2.103 & 0.886 & 1.270 & 3.000 \\
$\mathrm{DC}$ losses $(\mathrm{kWh})$ & 273.19 & 273.193 & 273.193 & 273.193 & 273.193 & 273.193 \\
Overall losses (kWh) & 647.79 & 644.233 & 639.913 & 644.473 & 643.033 & 636.553 \\
Overall losses reduction $(\%)$ & 0 & 0.549 & 1.216 & 0.512 & 0.734 & 1.735 \\
Grid power $(\mathrm{kWh})$ & 1400.46 & 1399.92 & 1399.2 & 1399.92 & 1399.44 & 1398.96 \\
\hline
\end{tabular}


Similarly, in the DC network, the total $\mathrm{AV}_{\mathrm{DC}-\mathrm{SOP}}$ for all the DC-SOP are shown in Figure 10. From the results, the highest value for the total $A V_{\mathrm{DC}-\mathrm{SOP}}$ is for the DC-SOP switch between feeders 51 and 66 in Case $H$. Furthermore, the total $A V_{D C-S O P}$ values for DC-SOP switch between feeders 51 and 55 (Case F) and between feeders 51 and 58 (Case $\mathrm{G}$ ) are also high. While the lowest total $\mathrm{AV}_{\mathrm{DC}-\mathrm{SOP}}$ value is for the $\mathrm{DC}$-SOP switch between feeders 55 and 58 (Case I). The results obtained in the above mentioned cases are summarized in Table 4. Hence, it can be concluded that by operating the DC-SOPs with a given value of total $\mathrm{AV}_{\mathrm{DC}-\mathrm{SOP}}$, the losses in the $\mathrm{DC}$ network can be reduced accordingly.

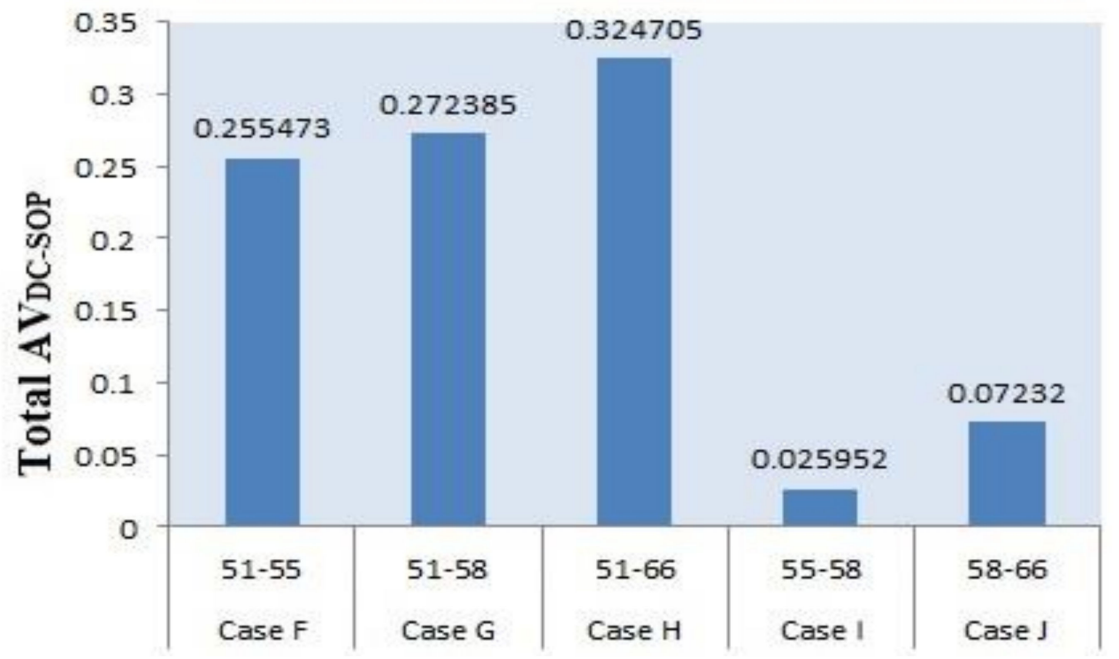

Figure 10. Total AV calculations for DC-SOP.

Table 4. Reducing in the network power losses for each $\mathrm{AV}_{\mathrm{DC}-\mathrm{SOP}}$ installed in the AC-DC hybrid distribution network for a 24-h period.

\begin{tabular}{lllllll}
\hline DC-SOP & No SOP & Case F & Case G & Case H & Case I & Case E \\
\hline $\mathrm{AV}$ DC-SOP & 0 & 0.255 & 0.272 & 0.324 & 0.025 & 0.072 \\
$\mathrm{AC}$ losses $(\mathrm{kWh})$ & 374.6 & 374.6 & 374.6 & 374.6 & 374.6 & 374.6 \\
$\mathrm{DC}$ losses $(\mathrm{kWh})$ & 273.193 & 271.472 & 271.297 & 270.777 & 272.523 & 272.348 \\
DC losses reduction $(\%)$ & 0 & 0.630 & 0.694 & 0.886 & 0.245 & 0.309 \\
Overall losses (kWh) & 647.79 & 646.072 & 645.897 & 645.372 & 647.123 & 646.948 \\
Overall losses reduction $(\%)$ & 0 & 0.265 & 0.292 & 0.373 & 0.103 & 0.130 \\
Grid power $(\mathrm{kWh})$ & 1400.46 & 1400.88 & 1402.08 & 1400.64 & 1400.16 & 1400.4 \\
\hline
\end{tabular}

\section{Conclusions}

To deal with the minimization of the network losses, many approaches can be used, and one of the methods is to change the original network topology in a loop or mesh to reduce the network power losses. In this study, a power flow analysis is solved for the AC-DC hybrid distribution network incorporating VSC with different control modes. The concept of a power electronic device known as soft open point (SOP) is analyzed and the modeling and operating principle of an AC-SOP and DC-SOP are formulated. The network reconfiguration approach is proposed in the AC-DC hybrid distribution network for the minimization of network power losses using AC-SOP and DC-SOP through an SOP/loop selection algorithm. The results of the proposed approach are verified through a case study showing its effectiveness. From the results it can be concluded that the approach of introducing the network reconfiguration through SOPs has improved the system performance, particularly in reducing network power losses. These results can be utilized in the planning and design of the AC-DC hybrid distribution network using different SOPs (AC-SOP and DC-SOP). 
Author Contributions: Conceptualization, M.O.K. and T.K.; Data curation, M.O.K. and T.K.; Formal analysis, A.W. and S.B.R.; Funding acquisition, S.B.R.; Investigation, M.O.K., A.W., T.K. and S.B.R.; Methodology, M.O.K., A.W., M.I.A. and T.K.; Resources, S.B.R.; Supervision, M.I.A. and S.B.R.; Validation, M.I.A.; Writing—original draft, M.O.K.; Writing—review \& editing, A.W. All authors have read and agreed to the published version of the manuscript.

Funding: This work was supported by "Development of Modular Green Substation and Operation Technology" of the Korea Electric Power Corporation (KEPCO).

Data Availability Statement: The data used to support the finding of this study are included within the article.

Conflicts of Interest: The authors declare no conflict of interest.

\section{References}

1. Exposito, A.G.; Conejo, A.J.; Canizares, C.A. Electric Energy Systems Analysis and Operation; CRC Press: Boca Raton, FL, USA, 2008.

2. Kalashani, M.B.; Nazarpour, D. New Symmetric and Hybrid Multilevel Inverter Topology Employed in Solar Energy Systems. Trans. Electr. Electron. Mater. 2018, 19, 304. [CrossRef]

3. Elsayed, A.T.; Mohamed, A.A.; Mohammed, O.A. DC microgrids and distribution systems: An overview. Electr. Power Syst. Res. 2015, 119, 407-417. [CrossRef]

4. Khan, M.O.; Jamali, S.Z.; Noh, C.-H.; Gwon, G.-H.; Kim, C.-H. A Load Flow Analysis for AC/DC Hybrid Distribution Network Incorporated with Distributed Energy Resources for Different Grid Scenarios. Energies 2018, 11, 367. [CrossRef]

5. Zhu, Z.; Liu, D.; Liao, Q.; Tang, F.; Zhang, J.; Jiang, H. Optimal Power Scheduling for a Medium Voltage AC/DC Hybrid Distribution Network. Sustainability 2018, 10, 318. [CrossRef]

6. Nguyen, P.H.; Kling, W.L.; Ribeiro, P.F. Smart power router: A flexible agent-based converter interface in active distribution networks. IEEE Trans. Smart Grid 2011, 2, 487-495. [CrossRef]

7. Cong, P.; Tang, W.; Lou, C.; Zhang, B.; Zhang, X. Multi-stage coordination optimisation control in hybrid AC/DC distribution network with high-penetration renewables based on SOP and VSC. J. Eng. 2019. [CrossRef]

8. Qu, Q.; Xu, D.; Zhai, Z.; Li, Q.; Zhang, W. Research on Development Technology of AC/DC Hybrid Distribution Network Construction in Smart Grid. IOP Conf. Ser.: Earth Environ. Sci. 2020, 10, 558. [CrossRef]

9. Long, C.; Wu, J.; Thomas, L.; Jenkins, N. Optimal Operation of Soft Open Points in Medium Voltage Electrical Distribution Networks with Distributed Generation. Appl. Energy 2016, 184, 427-437. [CrossRef]

10. Ji, H.; Wang, C.; Li, P.; Ding, F.; Wu, J. Robust Operation of Soft Open Points in Active Distribution Networks with High Penetration of Photovoltaic Integration. IEEE Trans. Sustain. Energy 2018, 10, 280-289. [CrossRef]

11. Cao, W.; Wu, J.; Jenkins, N.; Wang, C.; Green, T. Operating Principle of Soft Open Points for Electrical Distribution Network Operation. Appl. Energy 2016, 164, 245-257. [CrossRef]

12. Chub, A.; Vinnikov, D.; Blaabjerg, F.; Peng, F. A review of galvanically isolated impedance-source DC-DC converters. IEEE Trans. Power Electron. 2016, 31, 2808-2828. [CrossRef]

13. Romero-Ramos, E.; Gómez-Expósito, A.; Marano-Marcolini, A.; Maza-Ortega, J.M.; Martinez-Ramos, J.L. Assessing the loadability of active distribution networks in the presence of DC controllable links. IET Gener. Transm. Distrib. 2011, 5, 1105-1113. [CrossRef]

14. Bloemink, J.M.; Green, T.C. Benefits of distribution-level power electronics for supporting distributed generation growth. IEEE Trans. Power Del. 2013, 28, 911-919. [CrossRef]

15. Daelemans, G.; Srivastava, K.; Reza, M.; Cole, S.; Belmans, R. Minimization of steady-state losses in meshed networks using VSC HVDC. In Proceedings of the 2009 IEEE Power \& Energy Society General Meeting, Calgary, AB, Canada, $26-30$ July 2009.

16. Beerten, J.; Cole, S.; Belmans, R. Generalized steady-state VSC MTDC model for sequential AC/DC power flow algorithms. IEEE Trans. Power Syst. 2012, 27, 821-829. [CrossRef]

17. Cole, S.; Beerten, J.; Belmans, R. Generalized dynamic VSC MTDC model for power system stability studies. IEEE Trans. Power Syst. 2010, 25, 1655-1662. [CrossRef]

18. Go, H.-S.; Kim, J.-H.; Kim, E.-S.; Kim, C.-H. A study on the voltage sag during the EVs charging considering domestic data. J. Korean Inst. Illum. Electr. Install. Eng. 2015, 29, 37-46. [CrossRef]

19. Draxl, C.; Clifton, A.; Hodge, B.-M.; McCaa, J. The wind integration national dataset (wind) toolkit. Appl. Energy 2015, 151, 355-366. [CrossRef]

20. Sengupta, M.; Xie, Y.; Lopez, A.; Habte, A.; Maclaurin, G.; Shelby, J. The National Solar Radiation Data Base (NSRDB). Renew. Sust. Energ. Rev. 2018, 89, 51-60. [CrossRef] 